Kocaeli University
Kocaeli Journal of Science and Engineering
http://dergipark.org.tr/kojose

\title{
Pyrolytic Degradation Behavior of Biomass Seeds: Sour Cherry and Peach Seed
}

\author{
Meltem KIZILCA ÇORUH ${ }^{1, *}$ (D) , Hatice BAYRAKÇEKEN ${ }^{2}$ iD \\ ${ }^{1}$ Department of Chemical Engineering, Atatürk University, Erzurum, 25240, Turkey, ORCID: 0000-0001-8734-2502 \\ ${ }^{2}$ Department of Chemical Engineering, Atatürk University, Erzurum, 25240, Turkey, ORCID: 0000-0003-2472-9974
}

\begin{tabular}{l} 
Article Info \\
\hline Research paper \\
Received : September 08, 2020 \\
Accepted : October 05, 2020 \\
\\
Keywords \\
Biomass \\
Flyn-Wall-Ozawa \\
Kissinger-Akahira-Sunose \\
Pyrolysis \\
Thermal Analysis
\end{tabular}

\begin{abstract}
Pyrolytic degradation behavior of peach and sour cherry seed were investigated by thermal analysis techniques such as thermogravimetric (TG) and derivative thermogravimetric (DTG). Pyrolysis study of peach and sour cherry seed, which are the sources of plant biomass, were carried out under air flowrate of $10 \mathrm{~mL} \cdot \mathrm{min}^{-1}$ and heating rates of 2.5,5,10 and $20 \mathrm{~K} \mathrm{~min}^{-1}$ in the temperature range of 298$1173 \mathrm{~K}$ by means of thermal analysis techniques. The activation energy and pre-exponential factor were determined with different methods as Kissinger-Akahira-Sunose (KAS) and Flyn-Wall-Ozawa (FWO). Although the FWO method gives higher values, it was observed that all activation energy values calculated by both methods are compatible with each other. In addition, as the amount of volatile matter increases, the decomposition becomes difficult due to the increase in mass transfer resistance and pressure, so it was determined that the activation energy of the peach seed is higher than the sour cherry seed.
\end{abstract}

\section{Introduction}

Nowadays, non-renewable (fossil) and renewable energy sources are used to meet the energy needs. The use of fossil fuels (petroleum, coal and natural gas) is quite common due to the fact that the costs of production, transportation and storage are cheap and easy [1]. Research on the availability and use of alternative renewable energy sources in the opposite of this negative situation of fossil resources and the obtained fuels has accelerated in recent years. One of them is biomass and has a great potential of biomass as a source in which various liquid hydrocarbons are obtained, especially for energy purposes [2]. One of the biggest advantages of biomass is that it is grown and consumed everywhere. In addition, biomass provides a clean solution to environmental problems and does not hinder the natural cycle of carbon. Compared to fossil fuels, environmental damage is very low. In particular, the combustion of biomass and $\mathrm{CO}_{2} / \mathrm{SO}_{2}$ emissions, known as greenhouse gases are so small that they do not affect the environment. The reason why biomass is preferred to fossil fuels in the following years; the contribution of biomass to the negative effects of global warming, which is expected

\footnotetext{
* Corresponding Author: mkizilca@atauni.edu.tr
}

to lead the world to a great disaster, will be very low. Biomass conversion processes for utilizing biomass can be separated into three basic categories: physical (milling, drying, filtration, extraction), thermochemical (direct combustion, gasification, pyrolysis, carbonization, liquefaction) and biochemical [3]. Pyrolysis is one of the most used thermochemical methods. Pyrolysis is the phenomenon the thermal decomposition by inert atmosphere or vacuum of organic material. As a result of the pyrolysis process, solid, liquid and gas products are obtained. The distribution and properties of the products obtained as a result of pyrolysis depend on both the process parameters and the type of biomass used. Temperature, heating rate, pressure, entraining gas in the environment, reactor geometry, retention time and the use of catalyst are the parameters affecting pyrolysis. Besides, particle size, moisture content, organic structure, inorganic content, porosity, constant carbon ratio, elemental composition of the raw materials affects the pyrolysis efficiency and product properties [4]. In addition to examining the parameters for design, optimization and control of biomass pyrolysis processes, it is of great importance to clarify the kinetic mechanism. The pyrolysis process is a solid state degradation and its kinetic 
parameters are determined by thermal analysis techniques such as thermogravimetric (TG) and derivative thermogravimetric (DTG). By means of the thermogravimetric analysis which can be done in isothermal or non-isothermal conditions, by using the weight loss data generated during the decomposition of solids, the separately kinetics and kinetic parameters can be determined for the degradation steps representing the total reaction kinetics or the degradation of the basic components [5]. Turkey has a strong agricultural potential. There are various agricultural residues, mainly food residues. In this study, two different biomass materials, sour cherry and peach, were used. According to the ecological conditions of many countries, the material should be selected considering that it should use the most suitable and economical agricultural and forest products as an alternative energy source. The reason for choosing these materials is because they have different structural and chemical properties and also have significant potential in renewable energy sources [6, 7]. In Turkey, the production of peach and sour cherry is 668.000 and 184.000 tons/year, respectively.

In this study, the pyrolytic degradation behaviors of peach and sour cherry seed were investigated by thermogravimetric analysis using different heating rates. Kinetic triplets which were activation energy, preexponential factor and pyrolysis mechanisms were calculated for different decomposition steps and total reaction with Kissinger-Akahira-Sunose (KAS) and FlynWall-Ozawa (FWO) methods using data obtained from TG/DTG analysis.

\section{Materials and Methods}

\subsection{Materials}

Peach and sour cherry samples were purchased from a local supermarket in İstanbul, Turkey in February, 2019. Peach and sour cherry seeds were dried at room temperature and then ground to a $250 \mu \mathrm{m}$ particle size for use in experiments. Structural and elemental analyses of the samples were performed before the thermoanalytical measurements. The chemical composition of peach and sour cherry seed has been previously reported $[8,9]$.

\subsection{Thermal Analysis}

The thermal analysis was carried out with NETZSCH STA 409 PC Luxx apparatus. Correction by reference data was done with an empty crucible at measurement conditions, identical to the sample measurement conditions. Approximately $10 \mathrm{mg}$ of pattern was packaged in a platinum crucible. Experiments were taken with a pure nitrogen atmosphere flowrate of $10 \mathrm{~mL} \mathrm{~min}^{-1}$ under ambient conditions, over the temperature range of 298$1173 \mathrm{~K}$, at a heating rate of $2,5,10$ and $20 \mathrm{~K} \mathrm{~min}^{-1}$ and repeatable results were obtained. Platinum was used as the reference material. The experimental results obtained using the NETZSCH equipment were transformed to a MS Excel format file to draw TG-DTA curves and used to analyze the kinetics of dehydration.

\subsection{Kinetic Analysis}

In order to investigate the kinetics of the pyrolysis process, which is a solid phase decomposition process, the results obtained from thermogravimetric analysis was used. Active pyrolysis area determined by weight loss data obtained during biomass decomposition in thermogravimetric analysis and in order to determine kinetic parameters Kissinger-Akahira-Sunose (KAS) and Flyn-Wall-Ozawa (FWO) methods.

The Flyn-Wall-Ozowa (FWO) method Eq. (1), values of $1 / T$ are plotted against $\log \beta$ for each conversion value $(\alpha)$. Activation energy $(E a)$ is calculated from the slope of parallel lines and pre-exponential factor (A) is determined from the intercept of the plot of Eq. (1) $[5,10,11]$.

$\ln (\beta)=\ln \left(\frac{A E_{a}}{g(\alpha) R}\right)-5.331-1.052\left(\frac{E_{a}}{R T}\right)$

The Kissinger-Akahira-Sunose (KAS) method Eq. (2), values of $1 / T$ are plotted against the left side of equation for each $\alpha$ value. Activation energy $(E a)$ is calculated from the slope of parallel lines and preexponential factor (A) is determined from the intercept of the plot of Eq. (2) [5,11]:

$\ln \left(\frac{\beta}{T^{2}}\right)=\ln \left(\frac{A E_{a}}{R g(\alpha)}\right)-\frac{E_{a}}{R T}$

where $\beta$ is the heating rate, Ea is the activation energy, $\mathrm{T}$ is the obsolete temperature, $\mathrm{A}$ is the pre-exponential factor and $\mathrm{R}$ is the gas constant.

\section{Result and Discussion}

The TG-DTG curves corresponding to experiments carried out at four different heating rates $(2,5,10,15$ and $20 \mathrm{~K} \mathrm{~min}^{-1}$ ) in air atmosphere for the decomposition peach and sour cherry seed in Figure 1 and Figure 2, respectively. When the TGA diagrams given in Figures (1-2) were examined for each two samples, the different slopes were determined to have three weight loss zones. High substances of moisture and volatility. 


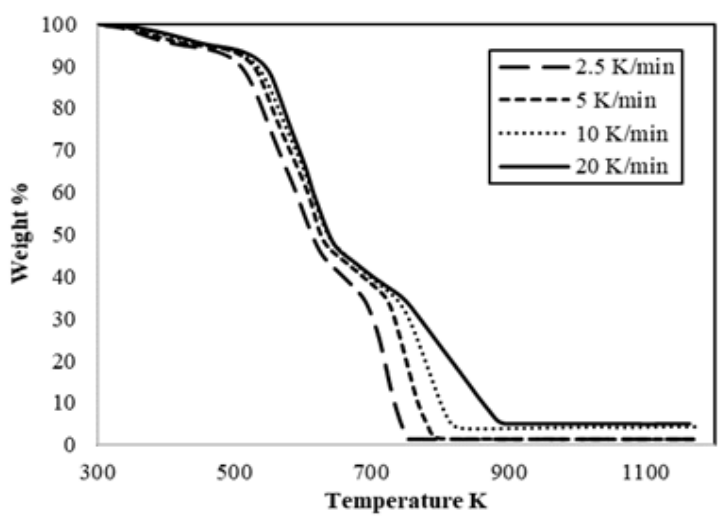

(a)

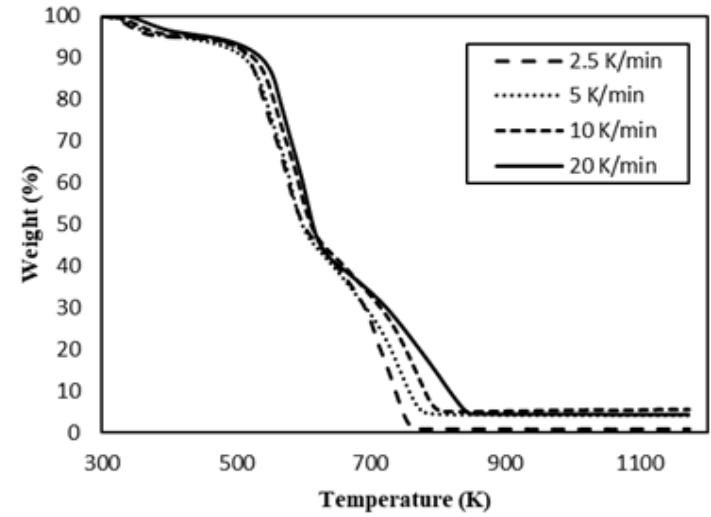

(b)

Figure 1. TG curves of a) sour cherry seed b) peach seed for different heating rates.

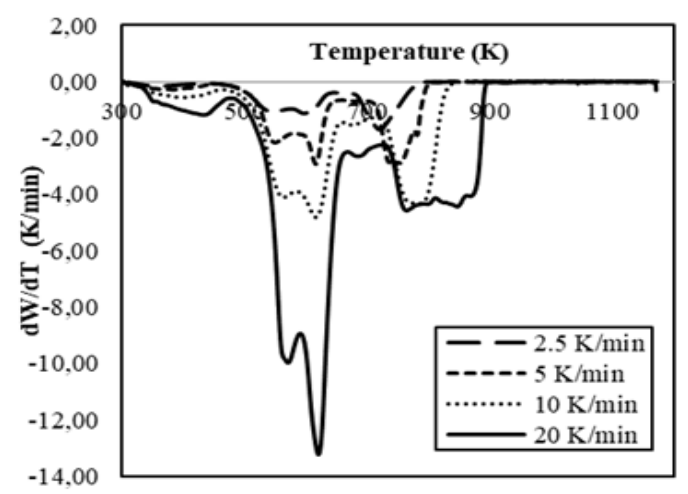

(a)

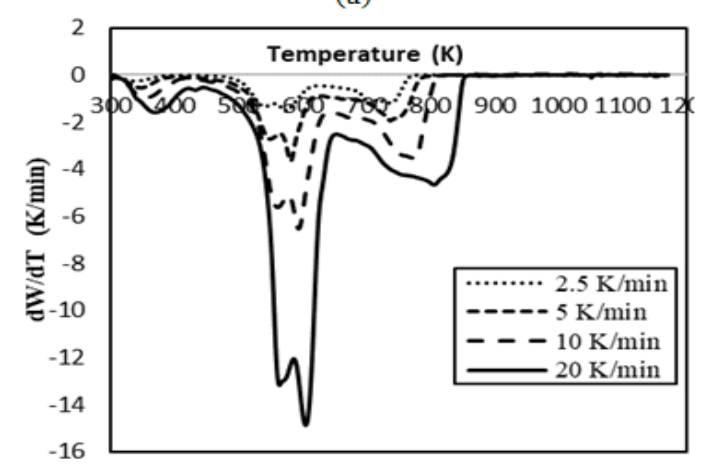

(b)

Figure 2. DTG curves of a) sour cherry seed b) peach seed for different heating rates.
The first region in the graphics is where it is separated from high humidity and volatile substances, and starting at $313 \mathrm{~K}$ and completed at $373 \mathrm{~K}$, approximately the second region, where the weight loss on the TG curve is most marked, characterizes the degradation of hemicellulose and cellulose. This region starts at $513 \mathrm{~K}$ for seeds species and lasts up to $653 \mathrm{~K}$. The third zone with slower loss of pain was identified as the thermal degradation zone of the lignin in the sample. The starting and ending temperature of the third zone were $653 \mathrm{~K}$ and $758 \mathrm{~K}$ respectively. Degradation continues in this region with gradually decreasing loss of mass. However, no significant change is observed in mass loss. After the mass loss becomes almost constant, only the carbon-rich solid product and ash remain from the lignocellulosic structure. Thus, when the temperature ranges of sour cherry and peach seed pyrolysis were examined, it was observed that the pyrolysis regions reflected the lignocellulosic structure of the biomass. $E_{a}$ values were determined with the slope of the $\ln \beta$ graph against $1000 / \mathrm{T}$ (Figure 3 (a, b) for KAS method and Figure $4(\mathrm{a}, \mathrm{b})$ for FWO method) between 0.1 and 0.9 values of fraction.

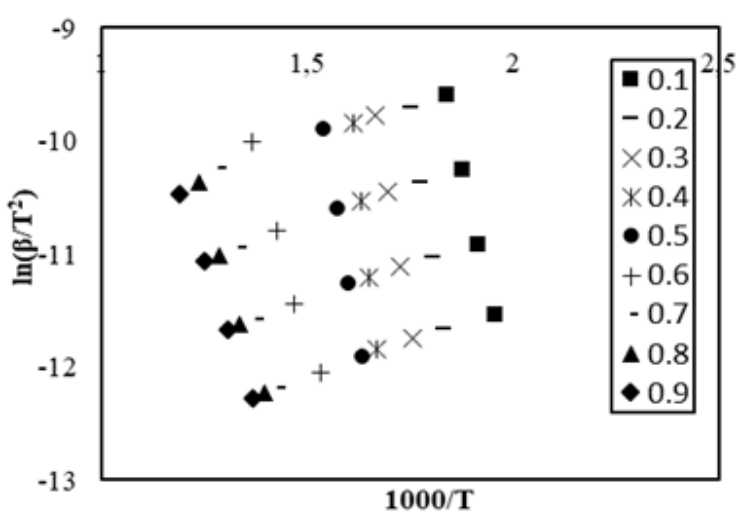

(a)

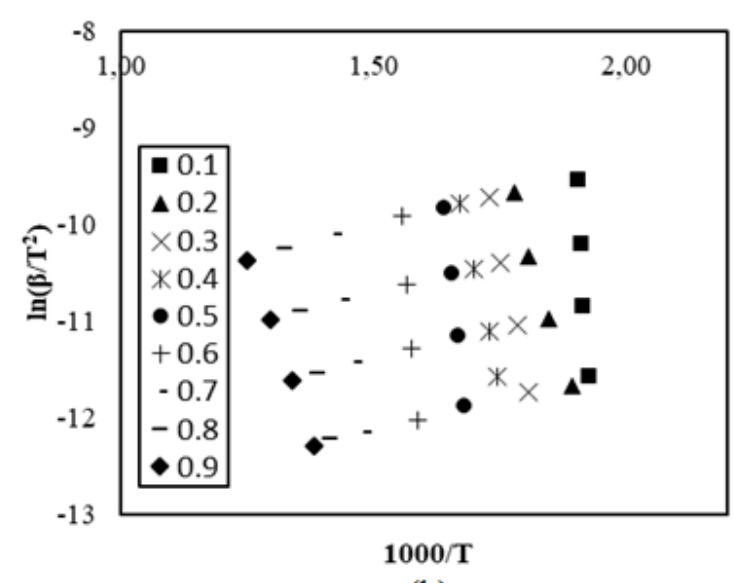

(b)

Figure 3. KAS method values for conversions from 0.1 to 0.9 ofthermal decomposition of a) sour cherry seed and b) peach seed. 


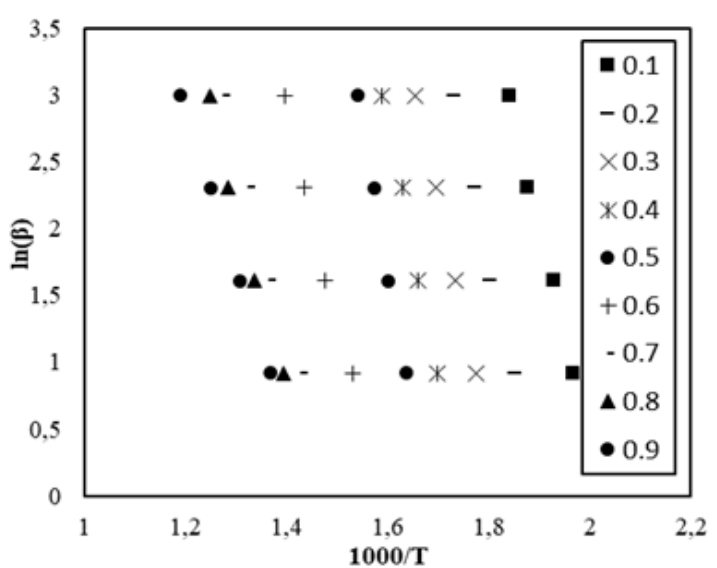

(a)

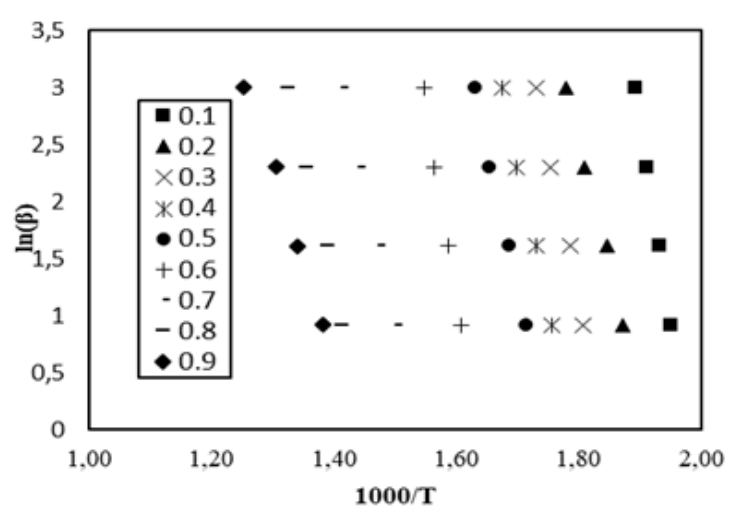

(b)

Figure 4. FWO method values for conversions from 0.1 to 0.9 of thermal decomposition of a) sour cherry seed and b) peach seed.

Activation energy, pre-exponential factor and regression coefficients calculated according to FWO and KAS methods (Eqs. (1-2)) are given in Table 1. It has been observed that there is a fluctuation in the activation energy by increasing the conversion fraction during the pyrolysis of peach and sour cherry seeds. The activation energy varies from 84.90 to $303.91 \mathrm{~kJ} / \mathrm{mol}$ in the conversion range of $0.1-0.9$. In the literature, there are many studies available showing the activation energy values for various biomass samples such as melon seed shell [12], chestnut shell [9], pistachio nutshell [13], tobacco waste [14], duckweed sample [15], and coffee husks [16]. The obtained activation energy is between 74-288 kJ mol-1. Thus, the activation energy values for sour cherry and peach seed calculated using the two models agree with the literature values. The change of the activation energy with the conversion fraction is related to the thermal degradation of the components of the biomass and is related to the thermal degradation of cellulose, hemicellulose and lignin. Increases and decreases in the activation energy indicate that the pyrolysis of the seeds is driven by multiple reaction mechanisms. When different kinetic methods were applied to the obtained data, the average activation energy values calculated by KAS and FWO methods were found as 125.77 and $135.59 \mathrm{~kJ} / \mathrm{mol}$ for seed in Table 1 and 204.93 and $213.47 \mathrm{~kJ} / \mathrm{mol}$ for peach seed in Table 2, respectively. The average of the exponential factor values tabulated in Tables (1-2) for sour cherry and peach seed were 27.77 and 44.34 for FWO and 13.03 and 34.12 for KAS methods, respectively, as calculated using Eqs. (1-2). The results showed that peach seed activation energy and pre-exponential values were higher than activation energy of sour cherry seed. The regression coefficients obtained from the kinetic analysis were found between 0.9746 and 0.9999 . The fact that these numbers are close to 1 shows that the kinetic model used is a theoretical model equation that can successfully describe pyrolytic degradation.

Table 1. Activation energies and pre-exponential factor from KAS and FWO methods for the decomposition of sour cherry seed.

\begin{tabular}{|c|c|c|c|c|c|c|}
\hline \multicolumn{2}{|l|}{ KAS } & \multicolumn{2}{l|}{ FWO } & \multicolumn{2}{l|}{$\mathrm{R}^{2}\left(\mathrm{~min}^{-1}\right)$} \\
\hline$\alpha$ & $\mathrm{E}_{\mathrm{a}}\left(\mathrm{kJ} \mathrm{mol}^{-1}\right)$ & $\mathrm{R}^{2}$ & $\mathrm{~A}\left(\mathrm{~min}^{-1}\right)$ & $\mathrm{E}_{\mathrm{a}}\left(\mathrm{kJ} \mathrm{mol}^{-1}\right)$ & & \\
\hline 0,1 & 17.93 & 0.9977 & 20.94 & 132.60 & 0.9958 & 32.31 \\
\hline 0.2 & 19.01 & 0.9930 & 32.21 & 145.71 & 0.9919 & 33.35 \\
\hline 0.3 & 17.56 & 0.9980 & 26.63 & 144.40 & 0.9999 & 31.76 \\
\hline 0.4 & 19.52 & 0.9999 & 44.89 & 159.64 & 0.9965 & 33.56 \\
\hline 0.5 & 175.25 & 0.9988 & 22.55 & 180.72 & 0.9994 & 36.47 \\
\hline 0.6 & 104.41 & 0.9912 & 7.11 & 128.89 & 0.9945 & 24.60 \\
\hline 0.7 & 114.80 & 0.9957 & 7.51 & 113.88 & 0.9932 & 20.44 \\
\hline 0.8 & 99.41 & 0.9960 & 4.37 & 116.52 & 0.9907 & 20.40 \\
\hline 0.9 & 84.90 & 0.9999 & 1.69 & 97.92 & 0.9999 & 17.02 \\
\hline Average & 125.77 & & 13.03 & 135.59 & & 27.77 \\
\hline
\end{tabular}


Table 2. Activation energies and pre-exponential factor from KAS and FWO methods for the decomposition of peach seed.

\begin{tabular}{|c|c|c|c|c|c|c|}
\hline \multicolumn{4}{|c|}{ KAS } & \multicolumn{3}{|c|}{ FWO } \\
\hline$\alpha$ & $\mathrm{E}_{\mathrm{a}}\left(\mathrm{kJ} \mathrm{mol}^{-1}\right)$ & $\mathrm{R}^{2}$ & $A\left(\min ^{-1}\right)$ & $\mathrm{E}_{\mathrm{a}}\left(\mathrm{kJ} \mathrm{mol}^{-1}\right)$ & $\mathrm{R}^{2}$ & $\mathrm{~A}\left(\min ^{-1}\right)$ \\
\hline 0,1 & 295.85 & 0.9746 & 57.81 & 303.91 & 0.9993 & 72.17 \\
\hline 0.2 & 175.51 & 0.9903 & 21.58 & 182.96 & 0.9960 & 42.13 \\
\hline 0.3 & 207.73 & 0.9919 & 33.46 & 215.13 & 0.9933 & 47.71 \\
\hline 0.4 & 181.973 & 0.9952 & 29.04 & 208.33 & 0.9967 & 44.91 \\
\hline 0.5 & 200.89 & 0.9991 & 72.45 & 205.41 & 0.9970 & 43.23 \\
\hline 0.6 & 290.03 & 0.9816 & 44.04 & 286.50 & 0.9966 & 56.28 \\
\hline 0.7 & 190.14 & 0.9956 & 22.20 & 194.70 & 0.9987 & 36.07 \\
\hline 0.8 & 178.37 & 0.9931 & 18.18 & 189.41 & 0.9947 & 33.19 \\
\hline 0.9 & 123.85 & 0.9987 & 8.34 & 223.29 & 0.9912 & 23.35 \\
\hline Average & 204.93 & & 34.12 & 213.47 & & 44.34 \\
\hline
\end{tabular}

\section{Conclusions}

Pyrolysis study of peach and sour cherry seed, which are the sources of plant biomass, are carried out at different heating rates by means of thermal analysis techniques (TG/DTG). In the TG curve of peach and sour cherry seed, thermal change was recorded in three regions, which are the separation of moisture and high volatile components, breaking of hemicellulose and cellulose and degradation of lignin at high temperature, depending on the temperature. Energy values calculated by KAS and FWO methods were found as 125.77 and $135.59 \mathrm{~kJ} / \mathrm{mol}$ for sour cherry seed and 204.93 and $213.47 \mathrm{~kJ} / \mathrm{mol}$ for peach seed, respectively. The average activation energy values calculated by both methods are compatible with each other. The proximity of these values indicates that preferred kinetic models can successfully identify pyrolytic degradation.

\section{References}

[1] Özsina G., Eren Pütün A., 2019. TGA/MS/FT-IR Study for Kinetic Evaluation and Evolved Gas Analysis of a Biomass/PVC Co-pyrolysis Process. Energy Conversion and Management, 182, pp.143153.

[2] Demirbaş A., 2001. Biomass Resource Facilities and Biomass Conversion Processing for Fuels and Chemicals. Energy Conversion and Management, 182, pp.143-153.

[3] Zhang L., Xu C., Champagne P., 2010. Overview of Recent Advances in Tthermo-chemical Conversion of Biomass. Energy Conversion and Management, 51, pp. 969-982.
[4] Samolada M. C., Stoicos T., Vasalos I. A., 1990. An Investigation of the Factors Controlling the Pyrolysis Product Yield of Greek Wood Biomass in a Fluidized Bed. Journal of Analytical and Applied Pyrolysis, 18, pp. 127-141.

[5] Kızılca M., Copur M., 2016. Investigation of the Thermal Decomposition Kinetics of Chalcopyrite Ore Concentrate Using Thermogravimetric Data. Chemical Engineering Communications, 203, pp. 692-704.

[6] Özçimen D., Ersoy-Meriçboyu A., 2008. A Study on the Carbonization of Grapeseed and Chestnut Shell. Fuel Process Technol, 89, pp. 1041-1046.

[7] Özçimen D., Ersoy-Meriçboyu A., 2010. Characterization of Bio Char and Bio-oil Samples Obtained from Carbonization of Various Biomass Materials. Renewable Energy, 35, pp. 1319-1324.

[8] Luz Bengoechea M., Sancho Begon I., Estrella I., Gomez-Cordoves C., Hernandez M. T., 1997. Phenolic Composition of Industrially Manufactured Pure'es and Concentrates from Peach and Apple Fruits. Journal of Agricultural and Food Chemistry. 45, 4071-4075.

[9] Özsin G., Eren Pütün A., 2018. Co-pyrolytic Behaviors of Biomass and Polystyrene: Kinetics, Thermodynamics and Evolved Gas Analysis, Korean J. Chem. Eng., 35, pp. 428-437.

[10] Kantürk Figen A., Sarı Yılmaz M., Pişkin S., 2010. Structural Characterization and Dehydration Kinetics of Kirka Inderite Mineral: Application of Nonisothermal Models. Materials Characterization, 61, pp. 640-647. 
[11] Kizılca M., Copur M., 2017. Thermal Dehydration of Colemanite: Kinetics and Mechanism Determined Using the Master Plots Method. Canadian Metallurgical Quarterly, 56, pp. 259-27.

[12] Ahmed A., Afolabi E. A., Garba M. U., Musa U., Alhassan A,. Ishaq I., 2019. Effect of Particle Size on Thermal Decomposition and Devolatilization Kinetics of Melon Seed Shell. Chemical Engineering Communications, 206, pp. 1228-1240.

[13] Isitan S., Ceylan S., Topcu Y., Hintz C., Tefft J., Chellappa T., Guo J., Goldfarb J. L., 2016. Product Quality Optimization in an Integrated Biorefinery: Conversion of Pistachio Nutshell Biomass to Biofuels and Activated Biochars via Pyrolysis. Energy Conversion and Management, 127, pp. 576-588.

[14] Polat S., Apaydin-Varol E., Eren Pütün A., 2016. Thermal Decomposition Behavior of Tobacco Stem Part II: Kinetic Analysis. Energy Sources, Part A: Recovery, Utilization, and Environmental Effects, 38, pp. 3073-3080.

[15] Liu H., Ahmad M. S., Alhumade H., Elkamel A., Sammak S., Shen B., 2020. A Hybrid Kinetic and Optimization Approach for Biomass Pyrolysis: The Hybrid Scheme of the Isoconversional Methods, DAEM, and a Parallel Reaction Mechanism. Energy Conversion and Management, 208, 112531.

[16] Setter C., Silva F. T. M., Assis M. R., Ataíde C. H., Trugilho P. F., Oliveira, T. J. P.,, 2020. Slow Pyrolysis of Coffee Husk Briquettes: Characterization of the Solid and Liquid Fractions. Fuel, 261, 116420. 